\title{
[header] How to perform open tracheal suction via an endotracheal
} tube

Credland N (2016) How to perform open tracheal suction via an endotracheal tube. Nursing Standard. 30, 35, 36-38. [Date of submission]: January 11 2016; [date of acceptance]: February 25 2016.

\section{Rationale and key points}

Tracheal suctioning involves the removal of pulmonary secretions from the respiratory tract using negative pressure under sterile conditions. Nurses should be aware of the risks associated with open tracheal suction via an endotracheal tube and recognise appropriate indications for tracheal suction. They should have the knowledge and competence to perform tracheal suction effectively and an understanding of the patient experience of the procedure.

- Respiratory assessment of the patient should be carried out to identify when tracheal suction is required.

- A suction pressure of $80-120 \mathrm{mmHg}$ is recommended, and suction should last no longer than 15 seconds.

- $\quad$ Reassurance and support should be given to the patient to minimise any discomfort and distress that may result from tracheal suction

\section{Reflective activity}

Clinical skills articles can help update your practice and ensure it remains evidence based. Apply this article to your practice. Reflect on and write a short account of:

1. How you think this article will change your practice when performing tracheal suction via an endotracheal tube.

2. How you could you use this resource to educate your colleagues.

Subscribers can upload their reflective accounts at: rcni.com/portfolio

\section{Author}

Nicola Credland Lecturer in Critical Care and Advanced Practice, University of Hull, Hull, England.

Correspondence to: $\underline{\text { n.credland@hull.ac.uk }}$

[Twitter]@credland nicki

\section{Keywords}

clinical skills, clinical procedures, endotracheal tube, respiratory assessment, respiratory care, suctioning, tracheal suction, ventilation 


\section{[Review]}

[Online]

\section{Preparation and equipment}

$>$ The nurse should complete a comprehensive respiratory assessment to identify signs and symptoms that indicate that tracheal suction is required.

$>$ The nurse should be aware of the potential risks and complications associated with open tracheal suctioning via an endotracheal tube.

$>$ The nurse should explain the procedure to the patient, discuss it and gain their informed consent. If the patient lacks capacity then the practitioner must act in their best interests in accordance with the requirements of the Mental Capacity Act 2005.

$>$ The nurse should ensure that the necessary equipment is available including:

○ Personal protective equipment.

- Apron.

- Sterile gloves.

- Non-sterile gloves.

- Protective glasses.

- A selection of flexible suction catheters.

- Suction meter

○ Suction tubing.

- A clinical waste bag.

The nurse should check that the suction meter is functioning correctly and set to the correct suction pressure $(80-120 \mathrm{mmHg})$.

\section{Procedure}

1. Wash your hands and put on non-sterile gloves, an apron and protective glasses.

2. Pre-oxygenate the patient using $100 \%$ oxygen for $30-60$ seconds.

3. Select the appropriate size of suction catheter. The following formula may be used to determine the appropriate size suction catheter: suction catheter size (French)

$=2 x$ (size of endotracheal tube -2 ).

4. Open the suction catheter packaging and attach the suction catheter end to the suction tubing, ensuring that the catheter remains in its sterile packaging.

5. Turn on the suction meterand re-check that it is at the correct pressure $(80-120 \mathrm{mmHg})$.

6. Put a sterile glove on the hand you are going to use to hold the suction catheter.

7. Remove the catheter from the packaging, ensuring it remains sterile.

8. Disconnect the endotracheal tube from the ventilator.

9. Advance the suction catheter gently into the endotracheal tube until resistance is felt when the catheter reaches the carina (Figure 2). Then withdraw the catheter by $1-2 \mathrm{~cm}$. 
10. Apply suction by occluding the suction port located at the proximal end of the suction catheter. Suction should be applied continuously rather than intermittently.

11. Withdraw the suction catheter slowly, while maintaining suction. The withdrawal should be smooth and take no longer than 15 seconds.

12. Reconnect the ventilator.

13. Dispose of the suction catheter in a clinical waste bag as per local policy guidelines. Dispose of any personal protective equipment.

14. Assess the effectiveness of the procedure, for example by observing the patient's respiratory rate and oxygen saturations, and reassure the patient.

15. If further suction is necessary or another attempt at suction is required a new suction catheter and a fresh sterile glove should be used each time.

16. Document the procedure in the patient's notes.

\section{Evidence base}

Tracheal suction involves the removal of pulmonary secretions from the respiratory tract using negative pressure under sterile conditions.

For open tracheal suction via an endotracheal tube,

A sterile flexible suction catheter is attached via tubing to a portable or wall-mounted suction meter. Tracheal suction improves airway patency and oxygenation. It is essential to ensure there are appropriate indications for suctioning as there are also associated risks (Pederson et al 2009). Indications for suctioning include (Coombs et al 2013)

- Audible secretions.

- Reduced oxygen saturation levels.

- Reduced breath sounds or chest movements.

- Coarse crackles on chest auscultation.

- Deterioration in arterial blood gases such as a reduction in oxygen or an increase in carbon dioxide.

- Evidence of cyanosis.

Since endotracheal suctioning is known to cause hypoxia, which can predispose the patient to cardiac dysrhythmias, the American Association of Respiratory Care (AARC) clinical practice guidelines recommend that patients should be pre-oxygenated with $100 \%$ oxygen before tracheal suction (AARC et al 2010). The instillation of saline into endotracheal tubes to loosen secretions provides little benefit and is no longer recommended (Thompson 2000).

It is essential that the correct suction pressure is used when undertaking tracheal suction. The minimum negative pressure necessary to achieve secretion clearance should be applied. This helps prevent the risk of atelectasis, hypoxia and mucosal damage, which may be attributed to applying excessive suction pressure (Pedersen et al 2009). Suction pressures of $80-120 \mathrm{mmHg}$ are recommended to avoid these complications (Pedersen et al 2009).

Suction using a large size suction catheter is associated with an increased risk of alveolar collapse and atelectasis (Pedersen et al 2009). The external diameter of the suction catheter should be less 
than $50 \%$ of the internal diameter of the tracheostomy tube, as represented by the equation: Suction catheter size (French) $=2 x$ (size of tracheostomy tube [Q: in French?] -2). See previous explanation This allows air to enter the lung during suction and prevents hypoxia and atelectasis (Day et al 2002).

The suction catheter should be inserted into the patient's endotracheal tube until resistance is felt. This resistance represents the catheter reaching the carina of the trachea (the junction between the right and left main bronchi) (Figure 1).The suction catheter should be withdrawn by $1-2 \mathrm{~cm}$ before suction is applied to avoid damage to the mucosa (Pedersen et al 2009).

\section{[Figure 1 Position of the carina]}

Suction should only be applied when withdrawing the suction catheter to minimise mucosal damage in the respiratory tract (Wood 1998). The withdrawal process should take no longer than 15 seconds (Pedersen et al 2009). Lengthy suction attempts are associated with hypoxia and damage to the tracheal mucosa (Pedersen et al 2009).

The frequency of suctioning should be informed by the viscosity and purulence of the secretions, the status of the airway and any changes in respiratory parameters. It should not be determined by rigid or routine timescales because of the risk of adverse side effects (Van de Leur et al 2003, Rolls et al 2007, Chaseling et al 2014)

The removal of secretions via tracheal suctioning has associated risks including (Pedersen et al 2009, AARC et al 2010):

- Bleeding.

- Hypoxia or hypoxaemia.

- Bronchoconstriction.

- Collapse of the alveoli and atelectasis.

- Ulceration and damage to the trachea.

- Haemodynamic instability.

- Increased intracranial pressure.

Tracheal suctioning can be unpleasant for the patient, causing them discomfort and distress. Patients have commented that it feels 'like a red hot poker going down my throat' and 'I feel as if I cannot breathe' This distress should be considered and time allowed to reassure and provide support to the patient before and following the procedure.

Closed endotracheal suction occurs when suctioning occurs via a sterile, sheathed catheter that is inserted into the ventilator system, which remains connected during suctioning (Figure 2) (Pedersen et al 2009). This technique is used in ventilated patients and minimises infection risk while maintaining respiratory support.

\section{[Figure 2 Performing closed-circuit tracheal suction]}

[Q: are you able to provide this image at high resolution?] No sorry! 


\section{Useful resources}

Mallett J, Albarran JW, Richardson A (Eds) (2013) Critical Care Manual of Clinical Competencies and Procedures. Wiley-Blackwell, Chichester.

\section{References}

American Association of Respiratory Care, Restrepo RD, Brown JM 2nd, Hughes JM (2010) AARC clinical practice guidelines: endotracheal suctioning of mechanically ventilated patients with artificial airways 2010. Respiratory Care. 55, 6, 758-764.

Coombs M, Dyos J, Waters D, Nesbitt I (2013) Assessment, monitoring and interventions for the respiratory system. In Mallett J, Albarran JW, Richardson A (Eds) Critical Care Manual of Clinical Procedures and Competencies. Wiley-Blackwell, Chichester, 63-171.

Day T, Farnell S, Wilson-Barnett J (2002) Suctioning: a review of current research recommendations. Intensive and Critical Care Nursing. 18, 2, 79-89.

Pedersen CM, Rosendahl-Nielsen M, Hjermind J, Egerod I (2009) Endotracheal suctioning of the adult intubated patient -- what is the evidence? Intensive and Critical Care Nursing 25, 1, 21-30.

Chaseling W, Bayliss S-L, Rose K, Armstrong L, Boyle M, Caldwel, J, Chung C, Girffiths, K, Johnson K, Rolls K and Davidson P (2014) Suctioning an Adult ICU patient with an artificial airway; Agency for Clinical Innovation NSW Government Version 2 Chatswood, NSW, Australia ISBN 978-1-74187-9520]

Thompson L (2000) Suctioning Adults with an Artificial Airway: A Systematic Review. http://joannabriggslibrary.org/index.php/ibisrir/article/view/396 (Last accessed: March 1 2016.)

Van de Leur JP, Zwaveling JH, Loef BG, Van der Schans CP (2003) Patient recollection of airway suctioning in the ICU: routine versus a minimally invasive procedure. Intensive Care Medicine. 29, 3, 433-436.

Wood CJ (1998) Endotracheal suctioning: a literature review. Intensive and Critical Care Nursing. 14, $3,124-136$.

Figure 2 - Flexible suction catheters

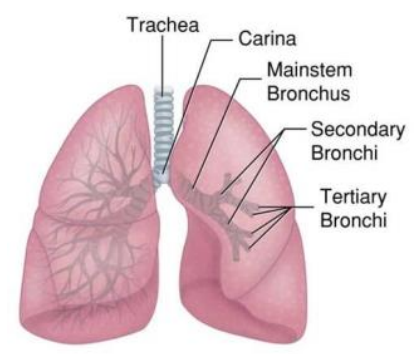

Figure 2 - Position of the carina 


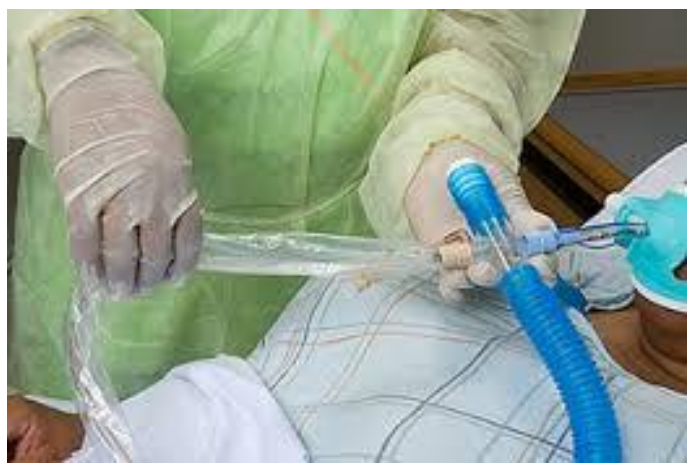

Figure 3 - Performing closed circuit tracheal suction 